\title{
ANÁLISE DA SATISFAÇÃo DO PÚBLICO IDOSO COMO USUÁRIO DE INTERFACES MÓVEIS
}

\section{ANALYSIS OF ELDERLY SATISFACTION AS A USER OF MOBILE INTERFACES}

\author{
Thaiana Anjos ${ }^{1}$, M.Sc \\ Leila Gontijo ${ }^{2}$, D.Sc
}
(1) Universidade Federal de Santa Catarina (UFSC) e-mail: anjos.thaiana@gmail.com

(2) Universidade Federal de Santa Catarina (UFSC)

e-mail: leila.gontijo@ufsc.br

Palavras-chave em português (Usabilidade, Interface Móvel, Terceira Idade)

A exclusão digital dos idosos provocada pela falta de usabilidade das interfaces móveis, como do telefone celular, é algo que pode ser contornada a partir do entendimento das barreiras e das necessidades do público idoso. Este trabalho estuda e investiga a relação do idoso com o celular, que é o equipamento eletrônico que mais cresce em vendas no mundo, por meio de um questionário de satisfação, a fim de identificar as necessidades, dificuldades e compreensão dos idosos quanto à facilidade, aos ícones, nomenclaturas e agrupamento das funções. Concluiu-se que os idosos precisam de funções fáceis de entender, terminologias mais claras e sem duplo sentido, além de uma interface mais amigável e funções agrupadas de acordo com a sua compreensão.

\section{Keywords in English (Usability, Mobile Interface, Elderly People)}

Digital exclusion of the elderly caused by lack of usability of mobile interfaces, like the mobile phone, is something that can be circumvented with the understanding of barriers and elderly's needs. This paper studies and investigates the relationship of the elderly with the cell phone, which is the fastest growing electronic equipment in sales worldwide, by the use of a satisfaction questionnaire, in order to identify their needs, difficulties and their understanding about the icons, classifications and grouping functions. It was concluded that older people need easier functions, clearer terminology without double meaning, besides a friendlier interface and functions that are grouped according to their understanding.

\section{Introdução}

A população brasileira e mundial está apresentando uma maior expectativa de vida e, consequentemente, a população de idosos está crescendo. Para o IBGE uma pessoa é considerada idosa quando tem uma idade superior a 60 anos [INSTITUTO BRASILEIRO DE GEOGRAFIA E ESTATÍSTICA, 2011]. De acordo com projeções do IBGE, a população brasileira possuirá mais de 73 milhões de idosos em 2060 [IBGE, 2013]. De acordo com o Censo Demográfico 2010, o Brasil possui mais de 20,5 milhões de idosos, sendo que a 


\section{$16^{\circ}$ \\ ERGODESIGN USIHC CINAHPA}

quantidade de mulheres é superior a de homens [IBGE, 2011]. Ainda de acordo com o Censo Demográfico 2010, a população brasileira é superior a 190,7 milhões de habitantes e, considerando esses números, a população de idosos no Brasil compreende mais de $10,7 \%$ da população. De acordo com a projeção para 2060, a população de idosos será mais de $33 \%$ da população brasileira.

Assim como cresce no mundo o número de idosos, cresce também o uso da Internet e de telefones celulares. Em janeiro de 2017 o Brasil registrou mais de 243 milhões de celulares, representando uma densidade de 117,65 cel/100 hab [TELECO, 2017a]. E em 2015, de acordo com uma pesquisa realizada pela Anatel, $68 \%$ dos usuários idosos utilizavam e possuíam um telefone celular [TELECO, 2017b].

O telefone celular é uma tecnologia que pode auxiliar o idoso a interagir com outras pessoas, visto que atualmente existem diversos tipos de aplicativos para este fim. Além de propiciar a comunicação, o celular disponibiliza aplicativos para entretenimento, busca de informações, ferramentas de escritório, entre outros. Porém, apesar de serem tão comuns, são tecnologias novas para eles e que, na maioria das vezes, não são totalmente compreendidas.

Um fator negativo do crescimento do uso de telefones celulares e da internet é a exclusão de inúmeras pessoas, como os usuários idosos, que não estão familiarizados com estas tecnologias, ainda mais quando elas são difíceis de entender, utilizar e aprender. Funções consideradas simples, como enviar uma mensagem, se tornam altamente frustrantes.

Neste contexto, áreas como a ergonomia, usabilidade, acessibilidade, design da informação, entre outras, auxiliam no desenvolvimento de interfaces e produtos com mais eficiência, eficácia e satisfação, contribuindo com uma maior independência e melhor qualidade de vida para este público.

Os resultados obtidos neste trabalho, a partir da $16^{\circ}$ Ergodesign - Congresso Internacional de Ergonomia e Usabilidade de Interfaces Humano Tecnológica: Produto, Informações Ambientes Construídos e Transporte

$16^{\circ}$ USIHC - Congresso Internacional de Ergonomia e Usabilidade de Interfaces Humano Computador

CINAHPA | 2017 - Congresso Internacional de Ambientes Hipermídia para Aprendizagem.

investigação da satisfação do uso do telefone celular pelo público, será possível auxiliar designers, desenvolvedores e equipes que projetam produtos e interfaces móveis a compreender melhor a realidade do público idoso.

A partir disso, esses profissionais poderão identificar características, recomendações e soluções que poderão ser utilizadas para projetar um conjunto de interfaces de celular voltado ao público idoso.

\subsection{Objetivo}

Este artigo tem por objetivo investigar a satisfação do uso do telefone celular pelo público idoso a fim de identificar as suas necessidades e as dificuldades enfrentadas durante a interação.

\section{Terceira Idade}

A terceira idade pode ser caracterizada como o grupo mais heterogêneo na sociedade, visto que as pessoas em geral começam a vida do mesmo modo, nascem com características e habilidades similares e quando se tornam idosos já adquiriram diferentes experiências e percepções, assim como já, possivelmente, tenham sofrido desgastes físicos e mentais em diferentes formas [PATTISON; STEDMON, 2006].

O envelhecimento pode ser descrito como um processo ou um conjunto de processos inerente a todos os seres vivos, que provoca alterações físicas e fisiológicas, expressando-se pela perda da capacidade de adaptação e pela diminuição da funcionalidade [ANJOS, GONTIJO, 2015].

Apesar de todos as alterações sensoriais que ocorrem com os idosos, entre elas destacam-se as alterações visuais, auditivas, cognitivas e de orientação, que ocorrem com maior intensidade, os idosos ainda se diferenciam pelas suas habilidades, gostos e experiências únicas de vida [ANJOS, GONTIJO, 2013]. Esses elementos influenciam em toda a possível aceitação e interação do idoso com a tecnologia.

Certas dificuldades ou deficiências, mesmo leves, 


\section{$16^{\circ}$ \\ ERGODESIGN USIHC CINAHPA}

podem se tornar um problema grave devido à inserção das tecnologias da informação em todas as engrenagens da vida social, doméstica ou profissional. Os computadores e seus programas são concebidos basicamente para usuários normais, ou seja, sem deficiências suscetíveis que possam impedir ou atrapalhar na interação com as interfaces [SPERANDIO; UZAN, 2007].

\subsection{O idoso e o telefone celular}

O telefone celular e todas as tecnologias móveis tornaram-se mais avançadas a cada ano. Os idosos são expostos a produtos muitas vezes não familiarizados e que, na maioria das vezes, podem causar um isolamento social e tecnológico. Os pesquisadores alertam que a sociedade se divide entre aqueles que sabem manusear um celular e os que não têm familiaridade com esses tipos de produtos, e que isso pode ameaçar a terceira idade de processos e convívios sociais inerentes à tecnologia [CARMINATTI ET AL., 2010].

Quando o idoso se sente motivado e ultrapassa a barreira psicológica imposta a ele mesmo, eles têm identificado algumas barreiras físicas nos equipamentos celulares, como displays muito pequenos, botões e teclados difíceis de usar, qualidade de som ruim, dentre outras. Além disso, algumas barreiras relacionadas a cognição e a falta de conhecimentos de jargões técnicos, como o não entendimento dos termos, a confusão devido à grande quantidade de funções, a não visualização de botões e links que estão representados em cores ilegíveis, entre outras.

\section{Ergonomia e Usabilidade}

A palavra ergonomia é derivada do grego ergon (trabalho) e nomos (leis). A International Ergonomics Association [IEA, 2011] em 2000 adotou a seguinte definição de ergonomia: "Ergonomia (ou fatores humanos) é uma disciplina científica preocupada o entendimento da interação entre seres humanos e outros elementos de um sistema, e a profissão aplica teoria, princípios, dados e métodos de concepção a fim de otimizar o bem-estar humano e o desempenho geral dos sistemas". Dessa forma, a ergonomia auxilia a $16^{\circ}$ Ergodesign - Congresso Internacional de Ergonomia e Usabilidade de Interfaces Humano Tecnológica: Produto, Informações Ambientes Construídos e Transporte

$16^{\circ}$ USIHC - Congresso Internacional de Ergonomia e Usabilidade de Interfaces Humano Computador

CINAHPA | 2017 - Congresso Internacional de Ambientes Hipermídia para Aprendizagem. entender a interação entre o idoso e o telefone celular, proporcionando teorias e princípios para otimizar o bem-estar do usuário.

Os estudos realizados são utilizados para desenvolver interfaces simples, intuitivas e fáceis de usar. Quando uma interface, programa ou aplicação possuem essas características e qualidades, pode-se dizer que há usabilidade.

De acordo com a NBR ISO 9241-11 (2002), a usabilidade é a capacidade que um produto tem de oferecer ao seu usuário, em um contexto específico de uso, a realização das tarefas e objetivos específicos com eficácia, eficiência e satisfação. A eficácia é a "acurácia e completude com as quais usuários alcançam objetivos específicos". A eficiência se refere aos "recursos gastos em relação à acurácia e abrangência com as quais usuários atingem os objetivos". Já a satisfação se refere a "ausência do desconforto e presença de atitudes positivas com o uso de um produto".

De acordo com Bias e Mayhew (2005) a usabilidade depende de alguns fatores, como por exemplo, se a funcionalidade do sistema está de acordo com as necessidades do usuário, se a resposta do sistema às tarefas realizadas pelo usuário está de acordo com a sua expectativa, dentre outros.

\subsection{Usabilidade e Interfaces Móveis}

Com a evolução dos celulares e o aumento das facilidades representadas pelo seu uso, houve o aumento também de aplicativos, funcionalidades e funções. Isto acarretou em menus complexos, obrigando o usuário a entrar em várias telas para se chegar onde deseja, diminuição da fonte utilizada, otimização dos espaços da tela, entre outros. Esses elementos trouxeram consequências significativas para os usuários em geral, sobretudo aos mais inexperientes, como os idosos.

\section{Procedimentos Metodológicos}

O método de pesquisa escolhido para este estudo foi o da pesquisa quali-quantitativa descritiva. A pesquisa qualitativa, de acordo com Wainer (2007),
Realização:

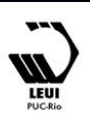




\section{$16^{\circ}$ \\ ERGODESIGN USIHC CINAHPA}

baseia-se na observação cuidadosa do usuário, estimulando-o a pensar e falar sobre algum tema. Já a pesquisa quantitativa, segundo Wainer (2007), é baseada na medida de variáveis objetivas, com o intuito de apurar opiniões, preferências e comparar resultados dos entrevistados, utilizando, por exemplo, questionários para adquirir as informações necessárias. Segundo Gil (2002) a pesquisa descritiva tem o objetivo primordial da descrição das características de determinadas populações ou fenômenos, sendo uma de suas características a utilização de técnicas padronizadas de coleta de dados, tais como questionários e a observação sistemática.

Para entender as dificuldades e as necessidades dos usuários idosos durante a interação com o telefone celular, utilizou-se um método empírico: Questionário de Satisfação. O Questionário de Satisfação serve para obter informações sobre o perfil do usuário, suas dificuldades, opiniões, interesses, ideias e outros aspectos do usuário sobre um assunto específico [BARROS, 2003].

Em um questionário, cada pergunta existente dependerá do tipo de dado que se quer coletar, qualitativo ou quantitativo, que depende do tipo de questionário aplicado. As perguntas fechadas são mais fáceis de serem analisadas e quantificadas. Mas, independentemente do tipo de questionário que é aplicado, é essencial que as perguntas sejam de fácil entendimento, evitando-se palavras e termos complexos.

O objetivo principal do questionário utilizado foi avaliar a interação do usuário idoso com o celular e foi dividido em cinco tópicos com os seguintes objetivos: 1) identificar a experiência do idoso com o celular, 2) quais são as suas impressões a respeito do uso do celular, 3) como é a aprendizagem do uso do celular, de novas funções entre outros, 4) qual a percepção do idoso a respeito da tela do celular e 5) qual é a percepção do idoso com a terminologia utilizada no celular. A seguir estão os tópicos mais detalhados:

1. Sua experiência com o celular: foram identificados se o idoso possui um celular; se não possui, por qual motivo; se possui, por qual o motivo; há quanto tempo ele utiliza o celular; quais funções ele utiliza, qual tamanho de tela do celular ele prefere; e se ele prefere uma tela sensível ao toque ou normal;

2. Suas impressões: foram identificadas a impressão do idoso quanto à utilidade e a facilidade de uso do celular;

3. Aprendizagem do celular: foram identificadas as primeiras interações dos idosos com o celular em relação à facilidade; quanto tempo durou o aprendizado; a facilidade de aprender a utilizar as funções, de descobrir novas funções e de relembrar nomes e uso das funções; se é excessivo a quantidade de comandos e telas para realizar uma função; e se as etapas para chegar a uma determinada função segue uma sequência lógica.

4. Tela do celular: foram identificados problemas em relação aos elementos gráficos da interface, como tamanho de letra e identificação dos ícones.

5. Terminologia do celular: foram identificadas se as palavras utilizadas, como os nomes de função e de comandos, são compreensíveis, se elas se relacionam com a atividade desempenhada e quais palavras são mais compreensíveis para um determinado contexto. Após esse item, foi acrescentado um tópico livre, onde os idosos podiam escrever comentários, sugestões e outras opiniões a respeito da sua experiência e do uso do celular.

Para verificar a validade do questionário, foi realizado um questionário-piloto e averiguar possíveis problemas e falta de compreensão do usuário idoso. Após as devidas constatações e posteriores alterações, o questionário final foi aplicado.

Após a aplicação do questionário, os dados coletados foram analisados e catalogados.

\subsection{Perfil da Amostra}

Os questionários foram aplicados com uma amostra de 5 idosos (questionário-piloto) e o questionário final para uma amostra de 41 pessoas, todos idosos, com mais de 60 anos, sendo 28 do sexo feminino e 13 do sexo masculino. Os idosos que responderam o questionário são docentes, 


\section{$16^{\circ}$ \\ ERGODESIGN USIHC CINAHPA}

discentes e funcionários do Núcleo de Estudos da Terceira Idade - NETI da UFSC e do

Departamento de Educação Física da UFSC.

O NETI busca participar efetivamente em prol do envelhecimento sadio: pela produção de conhecimentos da gerontologia, pela valorização do potencial dos idosos socialmente produtivos, pela promoção de idosos que adquirem e transmitem conhecimento à sociedade. Além disso, insere a pessoa idosa no contexto acadêmico e comunitário e tem o compromisso de lutar pelo desenvolvimento de políticas de atenção a pessoas idosas [NETI, 2012].

\section{Questionário de Satisfação}

Os questionários aplicados, tanto o inicial quanto o final, derivou do Questionnaire for User Interaction Satisfaction [QUIS; LABORATORY FOR AUTOMATION PSYCHOLOGY - LAP, 2015]. Primeiramente foi feita uma adaptação do QUIS 7 a fim de enquadrá-lo com os objetivos que se queriam atingir. O QUIS 7 foi desenvolvido para avaliar a interface de um sistema para computador, e o que se deseja é avaliar a interface de um dispositivo móvel, o celular. Após o desenvolvimento do questionário, foi realizado um teste-piloto a fim de validar esse questionário inicial e averiguar possíveis problemas e falta de compreensão do usuário. Foram constatados alguns problemas de compreensão e interpretação dos usuários e, por estes motivos, houve duas alterações significativas no questionário inicial.

A primeira alteração foi a respeito da escala utilizada. Em todos os três questionários: Quis, versão inicial e versão final do questionário, foi utilizada a escala Likert, porém com algumas diferenças. De acordo com Brandalise (2006), a escala Likert requer que "os entrevistados indiquem seu grau de concordância ou discordância com declarações relativas à atitude que está sendo medida. Atribui-se valores numéricos e/ou sinais às respostas para refletir a força e a direção da reação do entrevistado à declaração. As declarações de concordância devem receber valores positivos ou altos enquanto as declarações das quais discordam devem receber $16^{\circ}$ Ergodesign - Congresso Internacional de Ergonomia e Usabilidade de Interfaces Humano Tecnológica: Produto, Informações Ambientes Construídos e Transporte

$16^{\circ}$ USIHC - Congresso Internacional de Ergonomia e Usabilidade de Interfaces Humano Computador

CINAHPA | 2017 - Congresso Internacional de Ambientes Hipermídia para Aprendizagem. valores negativos ou baixos". O Quadro 1 apresenta os formatos da escala Likert utilizados nos questionários.

\begin{tabular}{|c|c|}
\hline & $\begin{array}{l}\text { Formato da escala Likert } \\
\text { utilizado }\end{array}$ \\
\hline QUIS & 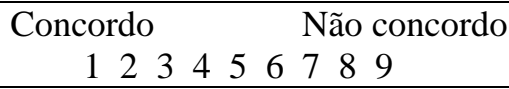 \\
\hline $\begin{array}{l}\text { Questionário } \\
\text { Inicial }\end{array}$ & \begin{tabular}{rllll} 
Concordo & \multicolumn{4}{c}{ Não concordo } \\
1 & 2 & 3 & 4 & 5
\end{tabular} \\
\hline $\begin{array}{l}\text { Questionário } \\
\text { Final }\end{array}$ & $\begin{array}{l}\text { 1. Não concordo totalmente } \\
\text { 2. Não concordo parcialmente } \\
\text { 3. Indiferente } \\
\text { 4. Concordo parcialmente } \\
\text { 5. Concordo totalmente }\end{array}$ \\
\hline
\end{tabular}

Quadro 1 - Formatos da escala Likert dos questionários.

Na escala Likert do Quis há muitos níveis para serem considerados e não há uma diferença significativa do nível 2 para 3 ou do 3 para o 4, por exemplo. Essa questão foi resolvida no questionário inicial, onde há um diferença do nível 1 para o 2 e do 2 para o 3 , por exemplo. Outra mudança que ocorreu foi devido à falta de compreensão de alguns idosos a respeito dessa disposição dos níveis. Para corrigir isso, foi identificado para cada nível o que ele representa: quanto um nível é mais favorável ou não do que o outro. Em suma, foi acrescentado em cada nível o seu rótulo correspondente.

A segunda alteração significativa não teve origem em alguma dificuldade e falta de compreensão do usuário, mas sim na identificação de mais características, atributos para melhorar a interface do celular. Foi acrescentado uma questão, na parte referente a terminologia utilizada no celular, sobre a melhor palavra que possa identificar uma função. Entre os sinônimos 'Chamada' e 'Ligação', por exemplo, qual palavra o usuário acha melhor para identificar a função de verificar todos os números de telefone que ligaram para ele, que ele ligou ou que não foi atendida.

\subsection{Aplicação do Questionário}

Primeiramente foi solicitada permissão à coordenadora do NETI para que o questionário pudesse ser aplicado para algumas turmas. Com o consentimento da coordenadora e dos professores de quatro turmas deu-se início à aplicação dos 


\section{$16^{\circ}$ \\ ERGODESIGN USIHC CINAHPA}

questionários.

Foi aplicado um questionário inicial em que foi verificado o entendimento do idoso com o conteúdo, as palavras e a escala empregados no questionário. Esse questionário contou com a participação de cinco idosos e, com os resultados obtidos, houve duas modificações no questionário final: na escala e no acréscimo de mais uma pergunta. O objetivo de acrescentar essa pergunta é que ficou constatado durante a aplicação do questionário que os idosos se confundiam com o significado dos nomes de algumas funções e comandos. Essa dificuldade foi contornada com o acréscimo da pergunta onde são comparadas palavras sinônimas para uma mesma função. $\mathrm{O}$ questionário final foi aplicado a outros idosos de outras turmas do NETI durante os intervalos de aula.

Logo depois, foi solicitada a permissão da coordenadora do Departamento de Educação Física para que pudesse aplicar o questionário às turmas de dança da terceira idade. Os questionários também foram aplicados durante os intervalos de aula.

\section{Resultados}

Responderam ao questionário 41 idosos, sendo 28 do sexo feminino e 13 do sexo masculino. Houve a maior participação de pessoas no início da terceira idade, aqueles com até 65 anos, representando 13 idosos (32\%).

Dentre os 41 participantes que responderam ao questionário, 34 deles utilizam celular $(83 \%)$ e 7 não utilizam (17\%). Dentre os idosos que não utilizam celulares, constatou-se que $4(57 \%)$ estudaram até o ensino fundamental, 2 (29\%) estudaram até o ensino médio e 1 pessoa não respondeu. Entre os idosos que não utilizam o celular, 5 deles $(71 \%)$ responderam achar difícil o uso do celular e, por este motivo, não querem possuir um. Já 2 idosos (29\%) responderam que não têm interesse em adquirir um celular.

De acordo como os idosos que possuem um celular, a compra do celular foi motivada $16^{\circ}$ Ergodesign - Congresso Internacional de Ergonomia e Usabilidade de Interfaces Humano Tecnológica: Produto, Informações Ambientes Construídos e Transporte

$16^{\circ}$ USIHC - Congresso Internacional de Ergonomia e Usabilidade de Interfaces Humano Computador

CINAHPA | 2017 - Congresso Internacional de Ambientes Hipermídia para Aprendizagem. especialmente para se comunicar com a família e amigos, representando 47\%. Porém, a utilidade do celular não está somente relacionada à comunicação com os familiares, mas também para eventuais emergências (34\%), assuntos de trabalho (12\%) e outros motivos (7\%). Outros motivos que motivaram o uso do celular se devem em razão da mobilidade que o celular possibilita para se comunicar com qualquer pessoa, para acessar a internet, dentre outros. A preocupação dos filhos com os pais idosos é outro motivo para a compra do telefone celular, que pode ser verificada quando uma idosa respondeu: "Fui obrigada a adquirir pela insistência dos meus filhos", e quando um idoso respondeu que possui porque recebeu de presente, fazendo com que se sentisse na obrigação de usar. Constatou-se que todos os idosos que cursaram o ensino superior responderam que utilizam celular.

A maioria dos usuários (76\%) possuem um celular há mais de 5 anos. Somente um dos participantes possui o celular por menos de 1 ano e 4 participantes possuem de 1 a 2 anos. Esse dado é fundamental para identificar as dificuldades e facilidades relacionadas ao aprendizado e como foi o início do uso do celular pelo participante.

De acordo com as respostas dos idosos, foi constatado que a maioria dos usuários utiliza poucos recursos que os celulares oferecem. O que todos fazem é ligar e receber chamadas (100\%). Dentro todos os idosos, 13 mandam mensagens (38\%), 10 utilizam a agenda de contatos e o despertador (29\% cada) e 8 fotografam e/ou filmam $(23,5 \%)$. O Gráfico 1 apresenta a quantidade de usuários que utiliza cada função.

Realização:




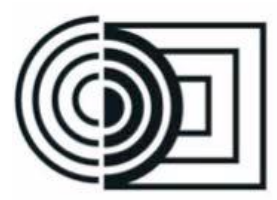

$16^{\circ}$ Ergodesign - Congresso Internacional de Ergonomia e Usabilidade de Interfaces Humano Tecnológica: Produto, Informações Ambientes Construídos e Transporte

$16^{\circ}$ USIHC - Congresso Internacional de Ergonomia e Usabilidade de Interfaces Humano Computador

CINAHPA | 2017 - Congresso Internacional de Ambientes Hipermídia para Aprendizagem.

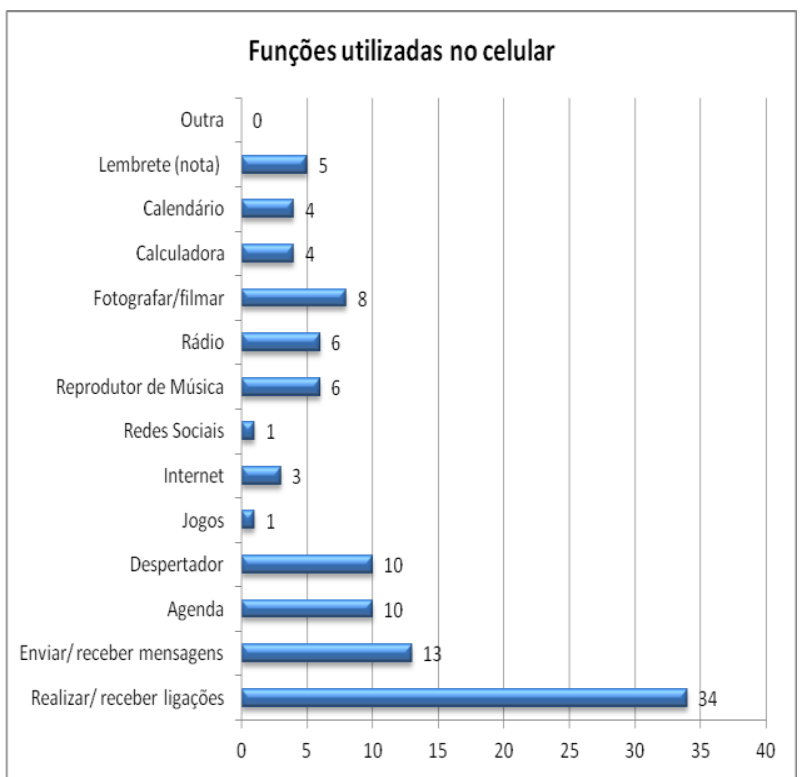

Gráfico 1 - Funções utilizadas pelos idosos.

Foi constatado que a maioria dos idosos, $56 \%$ dos participantes, preferem celulares que têm tela grande e $82 \%$ preferem tela não sensível ao toque.

Quanto às impressões do idoso a respeito do celular, foram feitas duas perguntas, quanto à utilidade e quanto à facilidade. Quanto à utilidade do celular, $74 \%$ dos participantes acham o celular útil, sendo que $56 \%$ concordaram que o celular é extremamente útil e $18 \%$ acham que ele é ligeiramente útil.

Quanto à facilidade de uso em relação ao uso das funções e comandos que podem ser executados no celular, os idosos que possuem o celular há mais tempo, mais de 4 anos, acham desde fácil a difícil, porém a maioria desses usuários $(43 \%)$ acham extremamente e parcialmente fácil o uso do celular. Já os idosos que possuem menos de 4 anos de uso acham, na sua maioria, difícil o uso do celular e alguns não acham nem fácil nem difícil.

Quanto à aprendizagem do celular, foram feitos sete questionamentos aos idosos. O Gráfico 2 apresenta a comparação da facilidade de iniciar o uso do celular quanto ao tempo que o idoso possui no uso do celular. Percebe-se que quanto mais tempo o idoso possui o celular, maior a chance de ele achar parcialmente fácil ou extremamente fácil o início do uso do celular. Nos questionamentos realizados e nas observações feitas por eles, constatou-se que iniciar o uso com os celulares mais antigos, de 5 anos atrás ou mais, a facilidade era maior, pois os celulares apresentavam poucas funções e se limitavam apenas a discar um número de telefone e apertar a tecla de chamar ou "o botão verde", como disse um dos participantes.

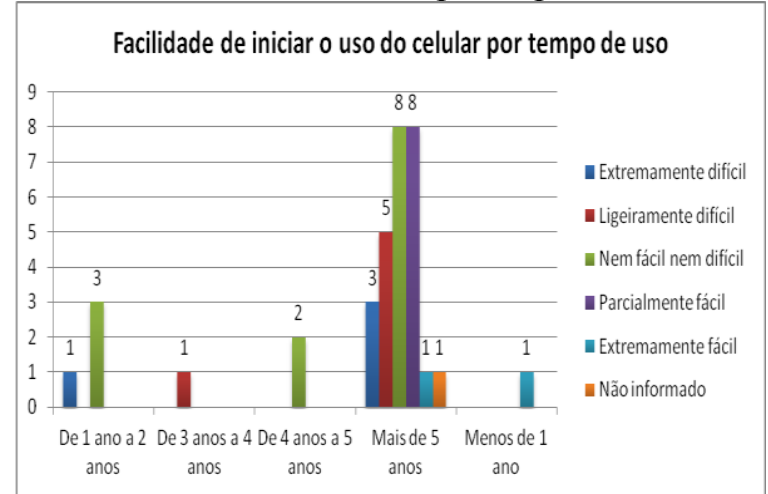

Gráfico 2- Distribuição dos idosos por tempo de uso e facilidade de iniciar o uso do celular.

Os usuários de celulares mais recentes, menos de 2 anos atrás, disseram que iniciar o uso do celular foi extremamente difícil, alguns disseram que não foi nem fácil nem difícil e um pessoa disse que foi extremamente fácil. De acordo com as explicações dadas pelos idosos, alguns consideraram que algumas funções foram complicadas de aprender, mas que a partir do momento que aprenderam foi fácil utilizar. Um idoso considerou extremamente difícil porque não entendia o funcionamento do celular e tinha "medo de estragar". Um segundo idoso relatou que foi extremamente fácil porque só usava o celular para discar um número, sem a utilização da agenda de contatos, e pressionava a tecla de chamar. Este último ainda disse se fosse para utilizar outras funções no celular iria achar muito difícil, mas como ele só utiliza para realizar uma chamada, ele achou extremamente fácil de aprender e utilizar.

A respeito da aprendizagem do uso do celular, a maioria dos idosos falou que o tempo de aprendizagem é parcialmente curto e nem curto nem longo, sendo que 3 idosos ainda falaram que é extremamente curto. A explicação dos idosos para isso foi a mesma para o critério de facilidade de uso, já que aprender a discar um número e pressionar a tecla de chamar é fácil. Porém, quando 


\section{$16^{\circ}$ \\ ERGODESIGN USIHC CINAHPA}

questionado sobre a facilidade da aprendizagem de novas funções, como encontrar a função do rádio, mandar uma mensagem etc., a maioria dos idosos respondeu que é extremamente e ligeiramente difícil.

Os idosos ainda foram questionados se eles acham que descobrir novas funções no celular é algo encorajador. A maioria dos idosos de 60 a 65 anos acha extremamente e parcialmente desencorajador, porém há idosos que acham extremamente e ligeiramente encorajador. Alguns idosos dessa faixa etária relataram que não têm interesse nem curiosidade de aprender novas funções no celular, e por isso, colocaram como desencorajador. Porém alguns idosos de 60 a 65 anos também disseram que tentam procurar novas funções, mas não conseguem achar sem a ajuda de alguém, como filhos e netos. Eles marcaram a opção de desencorajador já que não conseguem achar as funções sozinhos e não por falta de interesse em procurar. Mas também aqueles idosos que mesmo achando o celular difícil, tentam procurar e acham as funções, e esses idosos marcaram como encorajador.

Nas outras faixas etárias prevaleceram as opções extremamente e parcialmente desencorajadoras e ligeiramente encorajador. De 66 a 70 anos e 86 a 90 anos, os idosos acham que procurar novas funções é extremamente e parcialmente desencorajador. Esses idosos falaram que não têm interesse de procurar novas funções e também que o celular não possibilita uma facilidade para que eles procurem, já que eles não conseguem entender como ele funciona. Outros idosos também relataram que têm vontade de procurar, porém têm medo de mexer em alguma coisa que não podia e acabar estragando o celular. As outras faixas etárias têm idosos que acham ligeiramente encorajador e extremamente desencorajador descobrir novas funções.

Já 4 idosos de 81 a 85 anos disseram que procurar novas funções é ligeiramente encorajador. Pode-se perceber que alguns idosos são mais dependentes de alguém que os ensine, outros são curiosos o bastante para tentar aprender novas coisas, mas a maioria diz que a facilidade de uso em geral é difícil, dificultando ainda mais o uso por aqueles que têm algum receio de mexer e estragar o celular ou por aqueles que não conseguem entender o seu funcionamento.

Os idosos ainda foram questionados a respeito da facilidade que eles têm de relembrar nomes e uso das funções e as respostas ficaram divididas. 11 idosos responderam que é ligeiramente difícil e o mesmo número que é ligeiramente fácil, sendo que 8 falaram que é indiferente, 2 que é extremamente fácil e 1 que é extremamente difícil. Quando comparadas as respostas dos idosos por faixas etárias, estas continuam divididas, chegando à conclusão que alguns idosos possuem dificuldades para se lembrar do uso e nome das funções que eles basicamente não utilizam.

A respeito da quantidade de comandos do celular, a quantidade de idosos que responderam que $o$ número de telas e comandos do celular necessários para realizar uma função é extremamente excessivo e parcialmente excessivo totalizou 14. 10 idosos responderam que é extremamente adequada e ligeiramente adequada a quantidade de comandos. Por uma diferença pequena nas respostas, concluiu-se que é excessivo o número de telas e comandos.

De acordo com os idosos, na maioria usuários novatos, a grande dificuldade encontrada por eles no uso do celular se deve a dificuldade de entendimento das etapas para poder realizar uma função. Os idosos foram questionados se eles acham que o celular segue uma sequência lógica, uma sequência fácil de identificar, para executar uma função e eles responderam, na sua maioria, que o celular nunca ou quase nunca segue uma sequência fácil de identificar. Alguns idosos, porém, responderam que quase sempre as funções seguem uma sequência lógica, mas nas funções que eles realizam diariamente, de realizar uma chamada ou visualizar um contato. Quando questionados a respeito de outras funções, como mandar uma mensagem para quem nunca mandou ou configurar o despertador, todos eles falaram que quase nunca segue uma sequência lógica, de fácil identificação. 


\section{$16^{\circ}$ \\ ERGODESIGN USIHC CINAHPA}

Os questionamentos a seguir estão relacionados à interface gráfica e às questões de layout da tela do celular, como o tamanho da fonte e a compreensão dos ícones. A respeito da facilidade de leitura quanto ao tamanho das fontes, metade dos entrevistados respondeu que é parcialmente e extremamente fácil ler. E a respeito dos ícones, mais da metade disseram que é parcialmente e extremamente difícil de entender.

Por fim é perguntado aos idosos a respeito das terminologias empregadas no celular. Primeiramente é perguntado se as palavras utilizadas para os nomes das funções e dos comandos são de fácil entendimento para os idosos. Depois é perguntado se as palavras estão relacionadas com aquela função que eles estão desempenhando. De acordo com a maioria dos usuários as palavras utilizadas são confusas e não estão relacionadas com o que eles desempenham.

Depois foram perguntadas quais seriam as melhores palavras, dentre algumas opções, para representar melhor uma função. Aqui foram escolhidas somente algumas palavras mais utilizadas como nomes de funções e comandos na interface do celular. O Gráfico 3 contém a preferência dos idosos de acordo com cada grupo de palavras sinônimas: Chamada ou Ligação; Perdida ou Não Atendida; Recebida ou Atendida; Efetuada, Discada ou Realizada; Contatos, Lista Telefônica ou Agenda; Player de Música ou Reprodutor de Música; Ok ou Selecionar.

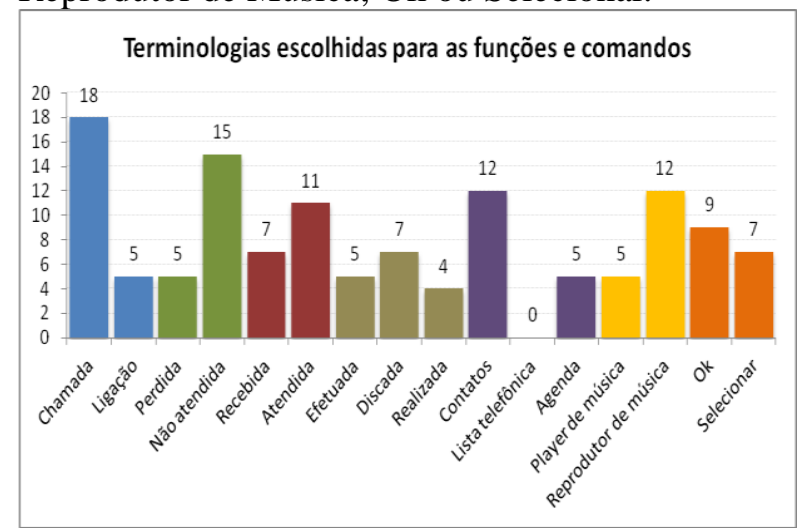

Gráfico 31 - Terminologias escolhidas pelos idosos para as funções e comandos.

Além das perguntas diretas, os idosos podiam $16^{\circ}$ Ergodesign - Congresso Internacional de Ergonomia e Usabilidade de Interfaces Humano Tecnológica: Produto, Informações Ambientes Construídos e Transporte

$16^{\circ}$ USIHC - Congresso Internacional de Ergonomia e Usabilidade de Interfaces Humano Computador

CINAHPA | 2017 - Congresso Internacional de Ambientes Hipermídia para Aprendizagem.

escrever livremente seus comentários, sugestões e outras opiniões a respeito do celular, do seu uso e de suas experiências. A seguir encontram-se alguns comentários.

"O celular é muito útil, mas é muito difícil de mexer. Acho que devia ser mais fácil."

"Meus filhos me deram porque se preocupam comigo, mas eu não gosto. Acho muito difícil."

“... Eu não gosto de mexer porque tenho medo de estragar. Mas a minha filha não tem paciência para me ensinar. Então eu só disco e atendo ligações."

"Eu acho fácil e não tenho nenhum problema com o meu celular. Uso a internet, rádio e agenda."

\section{Conclusão}

Concluiu-se que o principal motivo para os idosos não utilizarem o celular é a dificuldade de uso.

Verificou-se que a maioria dos idosos acha o celular útil e a maioria também possui um celular a mais de cinco anos. Porém alguns anos de uso não influenciam na utilização de todos os recursos que o celular disponibiliza, já que foi constatado que a maioria dos usuários utiliza poucos recursos que eles oferecem. O que os idosos basicamente fazem no celular é ligar e receber chamadas, mandar mensagem, acessar a agenda de contatos, utilizar o despertador e fotografar e filmar.

Verificou-se também que muitos idosos, quando questionados a respeito da facilidade de uso e tempo de aprendizagem, por exemplo, relataram que é fácil de usar e curto o aprendizado. Porém essa situação ocorre quando eles aprendem a discar um número e pressionar a tecla de chamar. Já quando questionados sobre a facilidade da aprendizagem de novas funções, como encontrar a função do rádio, mandar uma mensagem etc., a maioria dos idosos respondeu que é extremamente e ligeiramente difícil.

Percebeu-se que alguns idosos são mais dependentes que alguém os ensine e a maioria disse que o uso do telefone celular em geral é difícil, dificultando ainda mais para aqueles que 


\section{$16^{\circ}$ \\ ERGODESIGN USIHC CINAHPA}

$16^{\circ}$ Ergodesign - Congresso Internacional de Ergonomia e Usabilidade de Interfaces Humano Tecnológica: Produto, Informações Ambientes Construídos e Transporte

$16^{\circ}$ USIHC - Congresso Internacional de Ergonomia e Usabilidade de Interfaces Humano Computador

CINAHPA | 2017 - Congresso Internacional de Ambientes Hipermídia para Aprendizagem. têm algum receio de mexer e estragar o celular ou por aqueles que não conseguem entender o seu funcionamento. Por fim, a respeito dos ícones e das palavras utilizadas, mais da metade disse que é difícil de entender os ícones e que as palavras são confusas e não estão relacionadas com o que elas desempenham.

Embora poucos idosos utilizem várias funcionalidades que o celular oferece, foi constatado que a maioria não utiliza outras funções além das básicas (chamar e receber ligação) pela dificuldade encontrada em compreender aquelas funções.

\section{BIBLIOGRAFIA}

ANJOS, T. P. et al. Descomplicando o uso do telefone celular pelo idoso: desenvolvimento de interface de celular com base nos princípios de usabilidade e acessibilidade. Florianópolis: UFSC, 2013. 179 f. Dissertação (Mestrado) - Programa de Pós-Graduação em Engenharia de Produção, Universidade Federal de Santa Catarina, Florianópolis, 2013.

ANJOS, T. P. et al. Recomendações de usabilidade e acessibilidade para interface de telefone celular visando o público idoso. Production, v. 25, n. 4, p. 791-811, out./dez. 2015.

BARROS, V. T. O. Avaliação da interface de um aplicativo computacional através de um teste de usabilidade, questionário ergonômico e análise gráfica do design. Florianópolis: UFSC, 2003. 146 p. Dissertação (Mestrado) - Programa de Pós Graduação em Engenharia da Produção, Universidade Federal de Santa Catarina, Florianópolis, 2003.

BIAS, R. G.; MAYHEW, D. J. Cost-Justifying Usability: An Update for the Internet Age. São Francisco: Morgan Kaufmann, 2005.

BRANDALISE, L. T. Modelo de suporte à gestão organizacional com base no comportamento do consumidor considerando sua percepção da variável ambiental nas etapas da Análise do Ciclo de Vida do produto. Florianópolis: UFSC, 2006. 195 f. Tese (Doutorado) - Programa de PósGraduação em Engenharia de Produção, Universidade Federal de Santa Catarina, Florianópolis, 2006.

CARMINATTI, A. F. et al. Terceira idade e os eletroeletrônicos. Anais do $\mathbf{1 0}^{\circ}$ Congresso Internacional de Ergonomia e Usabilidade de Interfaces Humano-Tecnologia: Produto, Informações, Ambiente Construído e Transportes. 17 a 20 mai 2010. PUC-Rio/ Rio de Janeiro.

GIL, A. C. Como elaborar projetos de pesquisa. 4. ed. São Paulo: Atlas, 2002.

IBGE. Sinopse do Censo Demográfico 2010.

Disponível em:

<http://www.ibge.gov.br/home/estatistica/populacao/ censo2010/sinopse.pdf >. Acesso em: 5 out. 2011.

\section{IBGE. Projeção da População Brasileira.}

Disponível em:

<http://www.ibge.gov.br/home/estatistica/populaca o/projecao_da_populacao/2013/default_tab.shtm>. >. Acesso em: 16 mar 2017.

IEA. What is Ergonomics. Disponível em: <http://www.iea.cc/01_what/What\%20is\%20Ergono mics.html>. Acesso em: 19 jan. 2011.

\section{LABORATORY FOR AUTOMATION}

PSYCHOLOGY - LAP. Quis. Disponível em: <http://www.lap.umd.edu/quis/>. Acesso em 10 abr. 2015.

NETI. História. Disponível em: < http://neti.ufsc.br/historia/>. Acesso em: 02 out. 2012.

SPERANDIO, J. C.; GERARD, U. Ergonomia dos suportes técnicos informáticos para pessoas com necessidades especiais. In: Ergonomia (Pierre Falzon, org.). São Paulo: Edgard Blüncher, 2007.

PATTISON, M.; STEDMON, A. Inclusive design and human factors: designing mobile phone for older users. PsychNology Journal, v.4, n.3, pp. 267-284, 2006.
Realização:

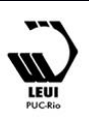




\section{$16^{\circ}$ \\ ERGODESIGN USIHC CINAHPA}

$16^{\circ}$ Ergodesign - Congresso Internacional de Ergonomia e Usabilidade de Interfaces Humano Tecnológica: Produto, Informações Ambientes Construídos e Transporte

$16^{\circ}$ USIHC - Congresso Internacional de Ergonomia e Usabilidade de Interfaces Humano Computador

CINAHPA | 2017 - Congresso Internacional de Ambientes Hipermídia para Aprendizagem.

WAINER, J. Métodos de pesquisa quantitativa e qualitativa para a Ciência Computação. In: Tomasz Kowaltowski ; Karin Breitman. (Org.). Atualização em informática 2007: Sociedade Brasileira de Computação e Editora PUC Rio, v., p. 221-262, 2007.

TELECO. Estatísticas de celulares no Brasil.

Disponível em: 〈http://www.teleco.com.br/ncel.asp>. Acesso em: 16 mar 2017a.

TELECO. Perfil dos usuários de celular.

Disponível em: <

http://www.teleco.com.br/ncel_usu.asp>. Acesso em: 16 mar $2017 b$.

\section{Agradecimentos}

Ao CNPq, por ter possibilitado e financiado esta pesquisa.

Ao NETI, por ter disponibilizado o acesso às turmas e apoiado a aplicação dos questionários de satisfação. 